\title{
Rockfall Impact Analysis of Typical Roadway Using Finite Element Simulation
}

\author{
Jinho Woo ${ }^{1}$ and Won-Bae $\mathrm{Na}^{{ }^{1}}$ \\ ${ }^{I}$ Department of Ocean Engineering, Pukyong National University, Busan, Korea
}

(Manuscript Received February 20 2012; Revised March 26, 2012; Accepted May 15, 2012)

\begin{abstract}
This study presents a rockfall impact analysis of a typical roadway. Dynamic finite element analyses using ANSYS AUTODYN are conducted to determine the effect of the drop heights $(5 \mathrm{~m}, 10 \mathrm{~m})$ on the damage to a roadway model. The Rockfall is modeled as a spherical shape with a weight of $400 \mathrm{~kg}$, and each drop height is converted to a corresponding impact velocity to save computational time. The roadway model is comprised of an asphalt layer, base layer, sub-base layer, and sub-grade layer. In this paper, the asphalt is modeled using a linear elastic model. The base layer, sub-base layer, and sub-grade layer are modeled using a Mohr-Coulomb model. From the analyses, the effects of the drop height on the damages and stresses are examined and discussed.
\end{abstract}

Keywords: Impact analysis, Rockfall, Asphalt concrete, Finite element analysis

\section{Introduction}

New roads are continually being built, and existing roads are being expanded. As a result, road cut slopes have been increasing rapidly. Unfortunately, this slope increase causes rockfalls. Rockfalls are a major hazard for roadways. Property losses occur annually as a result of rockfall every year. Therefore, specific engineering problems involve significant impact loading such as the rockfall impact on a roadway.

Asphalt is widely used as a construction material as well as a common material for pavement of roadway. Many studies have been performed for asphalt. Some of those have focused on the fracture mechanical characterization of asphalt [1-2]. Other studies have focused on the response of asphalt under moving loads of aircraft, trucks or cars [3-4]. However, an impact analysis is also a significant requirement in specific engineering problems such as the rockfall impact on a typical roadway.

*Corresponding author. Tel.: +82-51-629-6588, Fax.: +82-51-629-6590, E-mail address: wna@pknu.ac.kr

Copyright $\odot$ KSOE 2012.
This paper presents a rockfall impact analysis of a typical roadway. For this presentation, as an initial stage, a transient finite element dynamic analysis is carried out to capture the dynamic response of a roadway. Because the material model is quite significant for the impact simulation- the asphalt is modeled using a linear elastic model. The base layer, sub-base layer, and sub-grade layer are modeled a MohrCoulomb model. In addition, two different drop heights are considered. ANSYS AUTODYN, the general purpose finite element software, is used for explicit dynamic analyses.

\section{FEM Simulation}

\subsection{Rockfall modeling}

This work employs the explicit finite element method program ANSYS AUTODYN, which uses a Lagrangian formulation. The model consists of two parts: the roadway, and rockfall. An eight-node solid element is used for the model. 


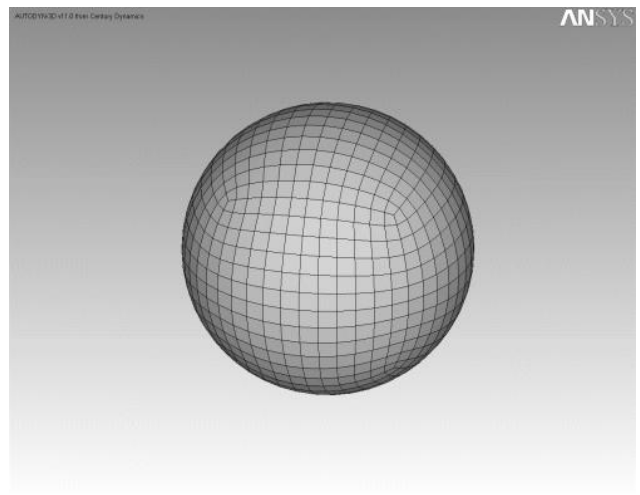

Fig. 1. Finite element mesh of rockfall.

Table 1. Material properties of rockfall.

\begin{tabular}{c|c|c}
\hline \hline $\begin{array}{c}\text { Density } \\
\left(\mathrm{kg} / \mathrm{m}^{3}\right)\end{array}$ & $\begin{array}{c}\text { Young' s modulus } \\
(\mathrm{GPa})\end{array}$ & $\begin{array}{l}\text { Poisson } \\
\text { ratio } v\end{array}$ \\
\hline 2650 & 100 & 0.29 \\
\hline
\end{tabular}

The rockfall part is modeled as a spherical shape, with a weight of $400 \mathrm{~kg}$, according to the "Guide for Installation and Management of Road Safety Facilities" [5]. The rockfall modeling is shown in Fig. 1. The material properties of the rockfall are shown in Table 1 [6].

For the impact analysis, two rockfall drop heights are considered: $5 \mathrm{~m}$ and $10 \mathrm{~m}$. To save computational time, the interval between the rockfall and asphalt is fixed at $3 \mathrm{~mm}$. Then, by using the principle of energy conservation, the following initial velocities for the rockfalls were obtained: $9.690 \mathrm{~m} / \mathrm{s}$ $(5 \mathrm{~m})$ and $13.998 \mathrm{~m} / \mathrm{s}(10 \mathrm{~m})$.

\subsection{Roadway modeling}

The roadway model is shown in Fig. 2, with each layer assumed to be perfectly bonded. The roadway model is comprised of an asphalt layer, base layer, sub-base layer, and sub-grade layer. The thicknesses of those layers are as follows: $160 \mathrm{~mm}$ for the asphalt layer, $150 \mathrm{~mm}$ for the base layer, 200 $\mathrm{mm}$ for the sub-base layer, and $500 \mathrm{~mm}$ for the subgrade layer.

The finite element model of roadway has the following dimensions: $3 \mathrm{~m}$ in the $\mathrm{x}$-direction, $3 \mathrm{~m}$ in the $\mathrm{z}$-direction, and $1.01 \mathrm{~m}$ in the y-direction, as shown in Fig. 3. The impact point is located at the center of the roadway model.

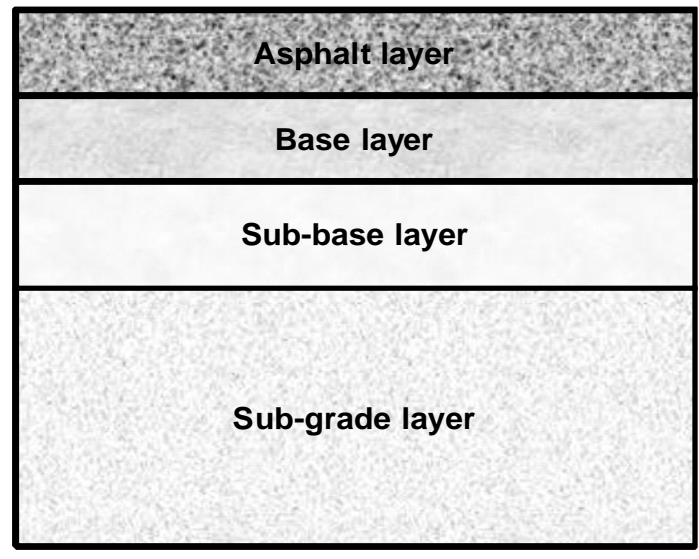

Fig. 2. Roadway cross-section.

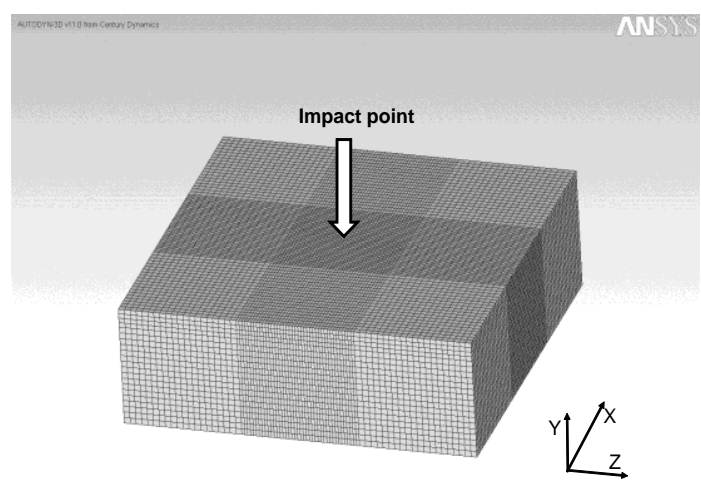

Fig. 3. Finite element mesh of roadway part and location of impact point.

\subsection{Material modeling}

In this study, asphalt is modeled using a linear elastic model. ANSYS AUTODYN requires four equations for material modeling: an equation of state (EOS), strength equation, failure equation, and erosion criteria. The asphalt material is composed as follows: (1) EOS: linear, (2) strength: elastic, (3) failure: principal stress, and (4) erosion criteria: geometric strain. The failure of the asphalt is initiated if the maximum tensile principal stress is reached. The erosion criteria are used to define a geometric strain erosion model, with an erosion strain of 0.1 . The material properties for the asphalt are given in Table 2 [7].

The base layer, sub-base layer, and sub-grade layer are modeled using a Mohr-Coulomb model. 
This model is an attempt to model the behavior of dry soils, rocks, and concrete. The linear function of the Mohr-Coulomb model is written as

$$
\tau_{f}=c+\sigma \tan \phi
$$

where $\tau_{f}$ is the shear strength, $c$ is the cohesion, $\sigma$ is the normal stress on the failure plane, and $\varphi$ is the angle of internal friction [8-9]. The material properties for the base layer, sub-base layer, and sub-grade layer are given in Table 2. Five gauge points are selected to obtain the response of the simulation. Table 3 show the locations of the impact point and gauge points.

Table 2. Material properties of base layer, sub-base layer, and sub-grade layer.

\begin{tabular}{|c|c|c|c|}
\hline \multicolumn{4}{|l|}{ Base layer } \\
\hline \multicolumn{2}{|c|}{ Density $\left(\mathrm{kg} / \mathrm{mm}^{3}\right)$} & \multicolumn{2}{|l|}{$2.2 \times 10^{6}$} \\
\hline \multicolumn{2}{|c|}{ Elastic modulus $(\mathrm{kPa})$} & \multicolumn{2}{|l|}{$2.41 \times 10^{5}$} \\
\hline \multicolumn{2}{|c|}{ Internal friction angle $\left(^{\circ}\right)$} & \multicolumn{2}{|l|}{46} \\
\hline \multicolumn{4}{|l|}{ Sub-base layer } \\
\hline \multicolumn{2}{|c|}{ Density $\left(\mathrm{kg} / \mathrm{mm}^{3}\right)$} & \multicolumn{2}{|l|}{$2.2 \times 10^{6}$} \\
\hline \multicolumn{2}{|c|}{ Elastic modulus $(\mathrm{kPa})$} & \multicolumn{2}{|l|}{$1.39 \times 10^{5}$} \\
\hline \multicolumn{2}{|c|}{ Internal friction angle $\left(^{\circ}\right)$} & \multicolumn{2}{|l|}{42} \\
\hline \multicolumn{4}{|c|}{ Sub-grade layer } \\
\hline \multicolumn{2}{|c|}{ Density $\left(\mathrm{kg} / \mathrm{mm}^{3}\right)$} & \multicolumn{2}{|l|}{$2.2 \times 10^{6}$} \\
\hline \multicolumn{2}{|c|}{ Elastic modulus $(\mathrm{kPa})$} & \multicolumn{2}{|l|}{$8.9 \times 10^{4}$} \\
\hline \multicolumn{2}{|c|}{ Internal friction angle $\left(^{\circ}\right)$} & \multicolumn{2}{|l|}{38} \\
\hline \multicolumn{4}{|c|}{ Table 3. Locations of impact point and gauge point. } \\
\hline & $\begin{array}{c}\mathrm{X}- \\
\text { coordinat }\end{array}$ & $\begin{array}{c}\mathrm{Y}- \\
\text { coordinate }\end{array}$ & $\begin{array}{c}\mathrm{Z}- \\
\text { coordinate }\end{array}$ \\
\hline Impact Point & $0 \mathrm{~mm}$ & $0 \mathrm{~mm}$ & $0 \mathrm{~mm}$ \\
\hline Gauge 1 & $0 \mathrm{~mm}$ & $-10 \mathrm{~mm}$ & $0 \mathrm{~mm}$ \\
\hline Gauge 2 & $0 \mathrm{~mm}$ & $-150 \mathrm{~mm}$ & $0 \mathrm{~mm}$ \\
\hline Gauge 3 & $0 \mathrm{~mm}$ & $-300 \mathrm{~mm}$ & $0 \mathrm{~mm}$ \\
\hline Gauge4 & $0 \mathrm{~mm}$ & $-500 \mathrm{~mm}$ & $0 \mathrm{~mm}$ \\
\hline Gauge 5 & $0 \mathrm{~mm}$ & $-800 \mathrm{~mm}$ & $0 \mathrm{~mm}$ \\
\hline
\end{tabular}

\section{Result}

Figs. 4 and 5 show the damage to the roadway part. Fig. 4 shows the result of a $5 \mathrm{~m}$ drop height, and Fig. 5 shows the result of a $10 \mathrm{~m}$ drop height. The dark parts in these figures represent the full damage $(0.9<$ Damage < 1.0). The other colors represent partial damage $(0.1<$ Damage $<0.9)$.

In Figs. 4 and 5, the damage is concentrated in the direct impact region and confined to the asphalt layer. No damage occurs to the base layer, sub-base layer, or sub-grade layer. When the drop height is increased, the damage increases in the direct impact region. The damages of peripheral are caused by the boundary condition and deflection of the impact point.

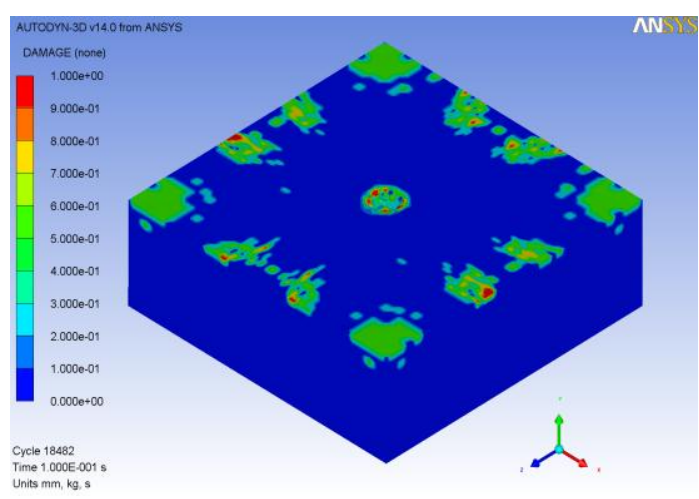

Fig. 4. Damage contours of roadway model (drop height $=$ $5 \mathrm{~m})$.

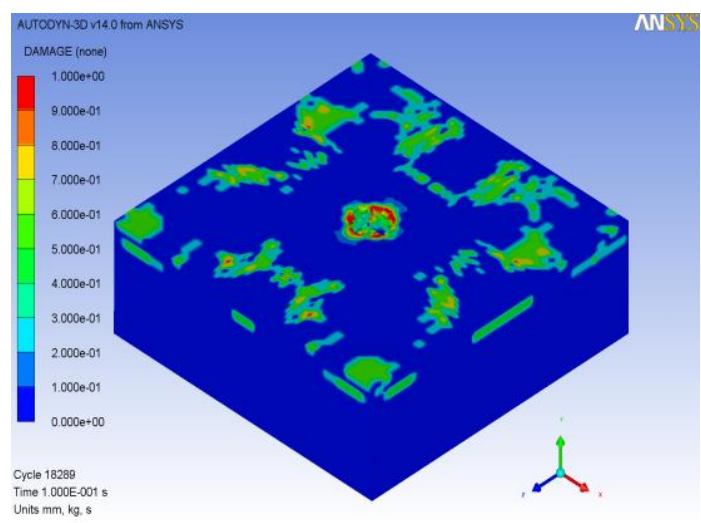

Fig. 5. Damage contours of roadway model (drop height $=$ $10 \mathrm{~m})$. 


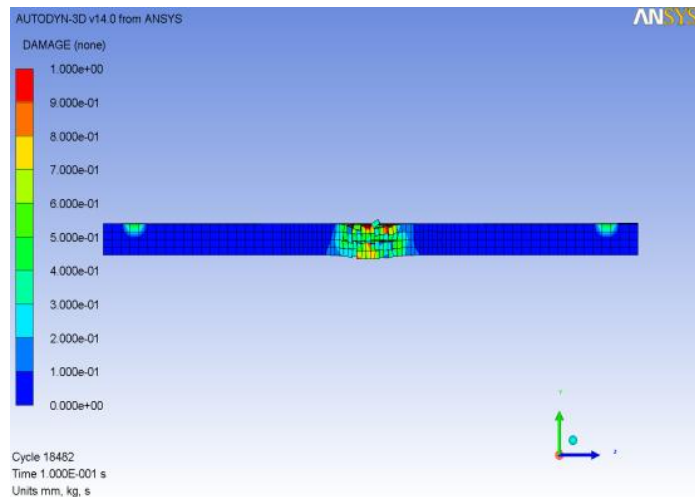

Fig. 6. Damage contours of asphalt layer (drop height $=5$ $\mathrm{m}$, time $=0.017 \mathrm{~s})$.

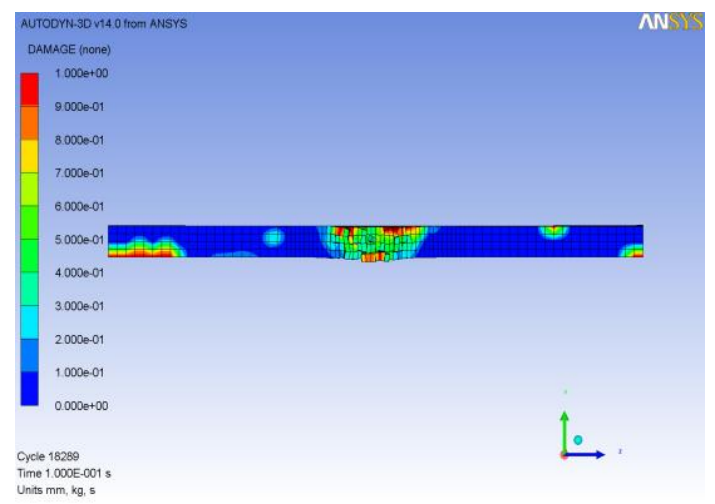

Fig. 7. Damage contours of asphalt layer (drop height $=10$ $\mathrm{m}$, time $=0.017 \mathrm{~s})$.

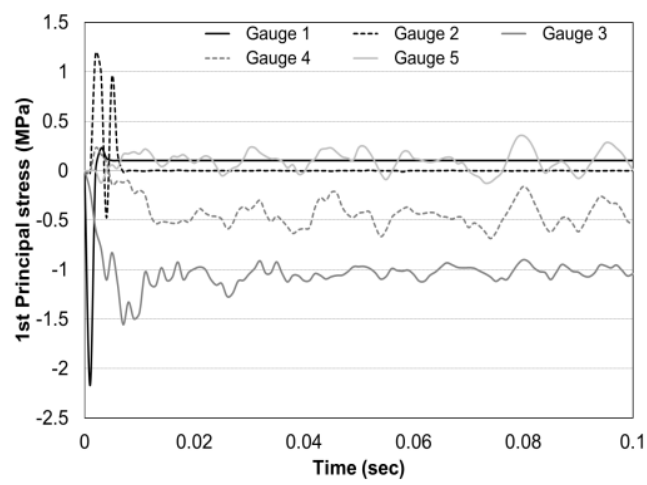

Fig. 8. 1st principal stresses of gauge points (drop height $=5 \mathrm{~m}$ ).

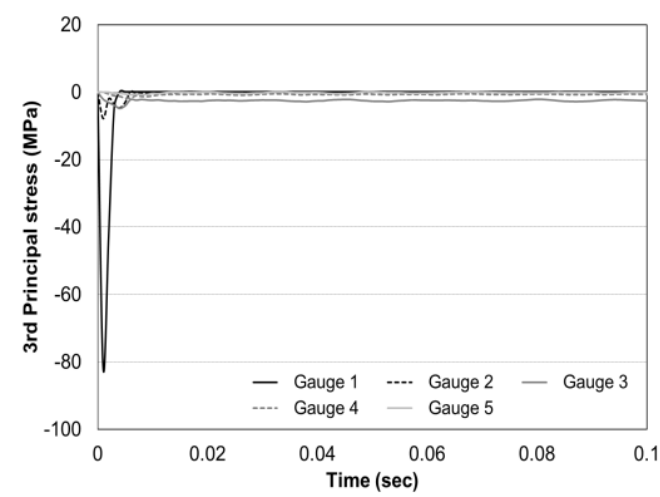

Fig. 9. 3rd principal stresses of gauge points (drop height $=5 \mathrm{~m}$ ).

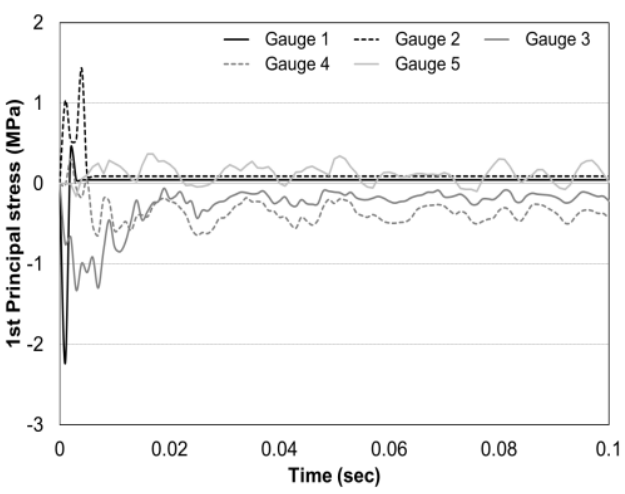

Fig. 10. 1st principal stresses of gauge points (drop height $=10 \mathrm{~m}$ ).

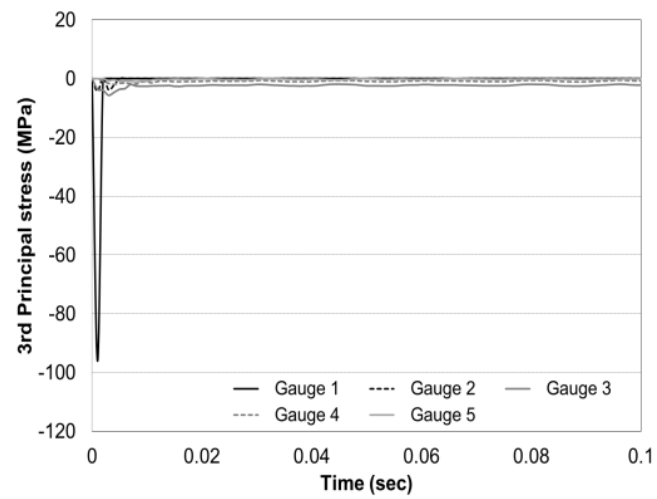

Fig. 11. 3rd principal stresses of gauge points (drop height $=10 \mathrm{~m}$ ). 
Figs. 6 and 7 show the damage to the asphalt layer at $0.017 \mathrm{~s}$ after the rockfall impact. These figures show a cross-section of the asphalt part. The damages occur in the direct impact region. These figures also show that the damage in the direct impact region occurs rapidly, a short time after impact.

Figs. 8, 9, 10, and 11 show the 1st and 3rd principal stresses at each drop height. Gauge 1 has the biggest compressive stress value of the drop heights. In the results for the principal stress, the compressive stress is concentrated in the direct impact region (gauge 1). The maximum compressive stresses of each drop height are as follows: the $5 \mathrm{~m}$ drop height is $82 \mathrm{MPa}$ and the $10 \mathrm{~m}$ drop height is $96.1 \mathrm{MPa}$.

\section{Conclusion}

From the rockfall impact analyses, the following conclusions are drawn in this paper.

$\checkmark$ The damage is concentrated in the direct impact region.

$\checkmark$ The damage is confined to the asphalt layer.

$\checkmark$ When the drop height increases, the damage increase in the direct impact region.

$\checkmark$ The damage in the direct impact region occurs rapidly, a short time after impact.

$\checkmark$ The maximum compressive stress is $82 \mathrm{MPa}$ when a $5 \mathrm{~m}$ drop height is used.

$\checkmark$ The maximum compressive stress is $96.1 \mathrm{MPa}$ when a $10 \mathrm{~m}$ drop height is used.

\section{References}

[1] D.M. Tan, E.K. Tschegg and S.E. Tschegg-Stanzl, Fracture mechanical characterization of asphalt aggregate mixtures at different temperature, Transaction on Engineering science, 6 (1994).

[2] R. Bandyopadhyaya, A. Das and S. Basu, $\mathrm{Nu}$ merical simulation of mechanical behavior of asphalt, Construction and Building Materials, 22 (2008) 1051-1058.

[3] G. Lacey, G. Thenoux and F. Rodriguez-Roa, Three-dimension finite element model for flexible pavement analyses based on field modulus measurements, The Arabian Journal for Science and Engineering, 33 (2007) 65-76.

[4] B. Sukamaran, Three-dimensional finite element modeling of flexible pavements, FAA World Airport Technology Transfer Conference, (2004).

[5] Safety Facilities the Ministry of land, Transport, and Maritime Affairs of Korea, Guide for Installation and Management of Road, (2000) 447-458.

[6] J.M. Gere, Mechanics of Materials, Thomson, USA, (2004).

[7] B.I. Kim and M.S. Lee, Development of fracture energy measurement system of asphalt mixture using Marshall Tester, Korean Society of Road Engineers, 11 (2009) 135-144.

[8] AUTODYN Theory manual, Century dynamics, (2005).

[9] B.M. Das, Principal of geotechnical engineering, Books/cole, USA, (2002). 